\title{
Anti-KIT designer T cells for the treatment of gastrointestinal stromal tumor
}

\author{
Steven C Katz ${ }^{1 *}$, Rachel A Burga', Seema Naheed ${ }^{1}$, Lauren A Licata', Mitchell Thorn', Doreen Osgood', \\ Cang $T$ Nguyen ${ }^{1}$, N Joseph Espat ${ }^{1}$, Jonathan A Fletcher ${ }^{3}$ and Richard P Junghans ${ }^{2}$
}

\begin{abstract}
Background: Imatinib mesylate is an effective treatment for metastatic gastrointestinal stromal tumor (GIST). However, most patients eventually develop resistance and there are few other treatment options. Immunotherapy using genetically modified or designer T cells ( $\mathrm{dTc}$ ) has gained increased attention for several malignancies in recent years. The aims of this study were to develop and test novel anti-KIT dTc engineered to target GIST cells.

Methods: Human anti-KIT dTc were created by retroviral transduction with novel chimeric immune receptors (CIR). The gene for stem cell factor (SCF), the natural ligand for KIT, was cloned into $1^{\text {st }}$ generation (SCF-CD3Z, 1st gen) and $2^{\text {nd }}$ generation (SCF-CD28-CD3Z, 2nd gen) CIR constructs. In vitro dTc proliferation and tumoricidal capacity in the presence of KIT+ tumor cells were measured. In vivo assessment of dTc anti-tumor efficacy was performed by treating immunodeficient mice harboring subcutaneous GIST xenografts with dTc tail vein infusions.

Results: We successfully produced the $1^{\text {st }}$ and $2^{\text {nd }}$ gen anti-KIT CIR and transduced murine and human T cells. Average transduction efficiencies for human $1^{\text {st }}$ and $2^{\text {nd }}$ gen dTc were $50 \%$ and $42 \%$. When co-cultured with KIT+ tumor cells, both $1^{\text {st }}$ and $2^{\text {nd }}$ gen dTc proliferated and produced IFNY. Human anti-KIT dTc were efficient at lysing GIST in vitro compared to untransduced T cells. In mice with established GIST xenografts, treatment with either $1^{\text {st }}$ or $2^{\text {nd }}$ gen human anti-KIT dTc led to significant reductions in tumor growth rates.
\end{abstract}

Conclusions: We have constructed a novel anti-KIT CIR for production of dTc that possess specific activity against KIT+ GIST in vitro and in vivo. Further studies are warranted to evaluate the therapeutic potential and safety of anti-KIT dTc.

Keywords: GIST, Adoptive cell therapy, Immunotherapy, and Designer T cells

\section{Background}

Gastrointestinal stromal tumor (GIST) is the most common GI mesenchymal neoplasm and nearly all GIST express KIT (CD117) [1]. Imatinib mesylate has been demonstrated to significantly prolong disease-free survival in the adjuvant setting and for patients with disseminated GIST [2,3]. Unfortunately, the majority of patients with metastatic GIST who are treated with imatinib develop resistance and subsequently progressive disease [4]. Therapeutic options are limited for patients who develop advanced GIST unresponsive to tyrosine

\footnotetext{
* Correspondence: skatz@chartercare.org

${ }^{1}$ Roger Williams Medical Center, Department of Surgery, Providence, RI/ Boston University School of Medicine, Boston, MA, USA

Full list of author information is available at the end of the article
}

kinase inhibitor (TKI) therapy. In an effort to address this clinical need, we sought to develop a T cell-based therapy for the treatment of KIT+ tumors including GIST.

Cell-based immunotherapy using tumor infiltrating lymphocytes (TIL) has shown success for specific diseases [5]. The potential impact of TIL therapy is limited by the inability to isolate TIL from the majority of patients with solid tumors [6]. The genetically modified or designer $\mathrm{T}$ cell $(\mathrm{dTc})$ strategy allows for the production of tumor-specific lymphocytes for any patient with a suitable target tumor antigen. Lymphocytes are isolated from peripheral blood and activated prior to retroviral transduction with a chimeric immune receptor (CIR) gene [7]. Expression of CIR on the surface of modified $\mathrm{T}$ cells allows for highly specific recognition of tumor cells expressing the cognate antigenic moiety.

\section{Biomed Central}

(c) 2013 Katz et al.; licensee BioMed Central Ltd. This is an Open Access article distributed under the terms of the Creative Commons Attribution License (http://creativecommons.org/licenses/by/2.0), which permits unrestricted use, distribution, and reproduction in any medium, provided the original work is properly cited. 
Retrovirus mediated introduction of tumor specific CIR into human $\mathrm{T}$ cells has resulted in $\mathrm{dTc}$ capable of activation, cytokine secretion, and target cell lysis [8-10]. Clinical success has recently been reported using $\mathrm{dTc}$ for the treatment of soft tissue sarcoma, melanoma, and leukemia $[11,12]$. We are not aware of prior efforts to treat GIST using dTc.

CIR typically exploit immunoglobulin or $\mathrm{T}$ cell receptor based specificity to target tumor antigens. Using an alternative strategy, we engineered a CIR that contains the natural ligand for KIT, which allows for recognition of KIT+ tumor cells. KIT-ligand (KL) or stem cell factor (SCF) was fused to the $\mathrm{CD} 3 \zeta$ chain component of the $\mathrm{T}$ cell receptor (1st generation, $1^{\text {st }}$ gen) or $\mathrm{CD} 3 \zeta+$ the CD28 co-stimulatory molecule (2nd generation, $2^{\text {nd }}$ gen). The $2^{\text {nd }}$ gen $\mathrm{dTc}$ express the construct that targets $\mathrm{KIT}+$ tumors while, at the same time, integrating CD28 co-stimulatory signals. $1^{\text {st }}$ and $2^{\text {nd }}$ gen dTc were produced and tested in vitro and in vivo to demonstrate their efficacy in destroying KIT+ tumor cells. The present report demonstrates encouraging initial results for anti-KIT dTc and provides the rationale for further pre-clinical testing of this novel immunotherapeutic anti-tumor agent.

\section{Methods}

\section{Retroviral vector construction}

First and second generation anti-KIT CIR were reengineered from the anti-CEA retroviral vector expression constructs previously described [7]. The extracellular domain of cKIT ligand ([Genbank:BC069733.1], cDNA clone MGC:97379) spanning the N-terminal start codon to the transmembrane start was PCR amplified from ATCC clone 010560371 using primers incorporating NcoI and BamHI restriction sites and cloned in-frame to replace the anti-CEA extracellular domain.

Extracellular domain of cKIT ligand:

(5'-gattccaggaattgatttcccatggcaaagaagacacaaacttg-3'

5'-ctaagctctagccaattgaattggatccgtgtaggctggagtctcc-3')

\section{Designer T cell production}

Human peripheral blood mononuclear cells (PBMC) were obtained from random donor whole blood filtrate (Rhode Island Blood Center, Providence, RI). Blood filters were washed with sterile PBS (Cellgro, Manassas, VA) and PBMC were isolated by density gradient separation with Histopaque (Sigma-Aldrich, St. Louis, MO) according to manufacturer directions. PBMC were seeded at a density of $2 \times 10^{6}$ cells $/ \mathrm{ml}$, and activated on anti-CD3 coated (OKT3, eBioscience, San Diego, CA) $750 \mathrm{ml}$ flasks with $2 \mathrm{ug} / \mathrm{mL}$ anti-CD28 (CD28.2, eBioscience) and $300 \mathrm{U} / \mathrm{mL}$ of human IL-2 in AIM V medium (Invitrogen, Grand Island, NY) supplemented with 5\% heat inactivated sterile human serum (Valley Biomedical, Winchester, VA). 293T-HEK phoenix amphotropic cells (Orbigen, Allele Biotechnology, San Diego, CA) were transfected with $50 \mu \mathrm{g} 1^{\text {st }}$ or $2^{\text {nd }}$ gen c-KIT ligand CIR retroviral plasmid using LipoD283 (SignaGen Laboratories, Rockville, MD). Viral supernatant was harvested for transduction of NIH-3T3 PG13 retrovirus packaging cells (ATCC: CRL-10686) cells that had reached $80 \%$ confluence. PG13 cells were cultured at $37^{\circ} \mathrm{C}$ and supernatant was harvested and filtered through $0.45 \mu \mathrm{m}$ filters (Corning, Corning NY) when cells reached $80 \%$ confluence. After 24-48 hours of culture, PBMC were seeded on retronectin-coated (20 ug/mL, Takara Bio, Otsu, Shiga, Japan) wells of a 6-well plate and were transduced with viral supernatant as described to create designer $\mathrm{T}$ cells [7]. Cells were transduced with supernatant containing either anti-KIT CIR vector $\left(1^{\text {st }}\right.$ gen) or anti-KIT CIR vector with additional CD28 moiety (2 ${ }^{\text {nd }}$ gen). Transduced $\mathrm{T}$ cells were maintained in AIM $\mathrm{V}$ medium supplemented with $5 \%$ heat inactivated sterile human serum and $100 \mathrm{IU} / \mathrm{ml}$ IL-2. Expression of KIT-specific CIR on designer $\mathrm{T}$ cells was evaluated by flow cytometric analysis of staining with anti-SCF mAb (Reprokine, Valley Cottage, NY) conjugated to APC (Chromaprobe, Maryland Hts, MO). Cells were also stained with antibodies against human CD3 (Sk7), CD4 (RPA-T4), CD8 (SK1), CD62L, CD45RO, CD197 (CCR7, 150503), and CD25 (M-A251), which were conjugated to FITC, PE, PerCP, APC, APC-Cy7, or Pe-Cy7 (BD Biosciences, Franklin Lakes NJ). For FoxP3 intracellular staining, samples were fixed, permeabilized, and stained with FoxP3 conjugated to $\mathrm{PE}$ as per manufacturer's protocol (BD).

\section{Cell proliferation assay}

Flow cytometry-based division assays were performed to analyze the proliferation of 1 st and 2 nd gen dTc in response to stimulation by KIT+ human GIST cell lines GIST882 [13] and GIST48, [14] both of which contain oncogenic KIT mutations. GIST882 was established from an untreated GIST, whereas GIST48 was established from a kinase-inhibitor resistant GIST which was progressing clinically after initial response to imatinib therapy. DTc were labeled with $1 \mu \mathrm{M}$ carboxyfluorescein diacetate succinimidyl ester (CFSE, Invitrogen) and were added at a 4:1 ratio with KIT+ GIST 882 and GIST 48 cells in a 96-well round-bottom plate, with $1 \times$ $10^{5} \mathrm{dTc}$ added per well. GIST48B cells [15], which have minimal KIT surface expression, were used as a negative control initially. MC38 murine colorectal carcinoma cells were also used as negative controls to ensure complete absence of human KIT on the cell surface. Tumor cells were irradiated at 5000 rad. Co-culture 
was incubated for 5 days, at which point supernatant was isolated and cells were analyzed by flow cytometry. Supernatant was analyzed by cytometric bead array for IFN- $\gamma$ levels (BD Biosciences). Cytokine production results were also quantified by human IFN- $\gamma$ ELISA assay for confirmation (Biolegend).

\section{Cytotoxicity assays}

$1^{\text {st }}$ and $2^{\text {nd }}$ gen dTc were cultured with KIT+ GIST 882 or GIST 48 cells in order to evaluate their cytotoxic ability in an LDH assay (Roche, Indianapolic, IN) performed according to the manufacturer's protocol. Tumor cells were irradiated at $5000 \mathrm{G}$ for 50 minutes. Cytotoxic ability was evaluated for $1^{\text {st }}$ gen $\mathrm{dTc}, 2^{\text {nd }}$ gen $\mathrm{dTc}$, and untransduced human $\mathrm{T}$ cells, which were added at various effector-to-target ratios. Cytotoxicity results from the LDH assay were further confirmed by flow cytometric analysis of tumor cell death. GIST cells were irradiated as previously described and labeled with CFSE while dTc were unstained; loss of CFSE+ cells was analyzed with flow cytometry.

\section{In vivo tumor studies}

Six-week-old male immunodeficient mice (NU/J) were purchased from Jackson Laboratories (Bar Harbor, ME) and experiments were conducted in compliance with the guidelines of the Roger Williams Medical Center Institutional Animal Care and Use Committee. The GIST cell lines were maintained at $37^{\circ} \mathrm{C}$ in IMDM with $1 \%$ l-glutamine (Invitrogen) supplemented with 15\% FBS, and 1\% Penicillin/Streptomycin/Amphomycin (Cellgro). We administered bilateral subcutaneous flank injections of $3 \times 10^{7} \mathrm{KIT}+$ GIST 882 cells in $200 \mathrm{ul}$ sterile PBS. DTc or untransduced human $\mathrm{T}$ cells were injected $\left(1 \times 10^{7}\right.$ in 200 ul PBS) via tail vein. For experimental groups with IL-2, Alzet 7-day microosmotic pumps (Durcet, Cupertino CA) were filled with IL-2 according to the manufacturer's protocol and implanted subcutaneously. Pumps were set to deliver at a rate of $10,000 \mathrm{IU} / \mathrm{h}(550 \mathrm{pg} / \mathrm{h})$. Tumors were measured in two dimensions with calipers, and measurements were obtained daily from the time of $\mathrm{T}$ cell injection until the conclusion of the study. The average of right and left flank tumors was used for each mouse, and measurements were normalized to initial tumor size. After sacrifice, tumors were excised and sent to the University of Massachusetts, Worchester Medical Center Experimental Pathology Service Core, for histological sectioning and staining. Sections were stained for routine H\&E and anti-CD3 immunohistochemistry. Slides were analyzed at the Pathology Department at Roger Williams Medical Center, and photographs were taken under 10x and 40x magnification.

\section{Statistics}

Statistics were calculated using GraphPad Prism V5.00 for Windows (GraphPad Software, San Diego, CA). Statistical significance for proliferation and cytotoxicity assays was determined using the two-tailed Student $t$ test, and values with $\mathrm{p} \leq 0.05$ were classified statistically significant. Tumor size median values are presented and logistic regression was used to compare growth curve slope and elevation among groups. Cell proliferation analysis with calculation of division peaks was performed using FlowJo software (Treestar, Ashland, OR).

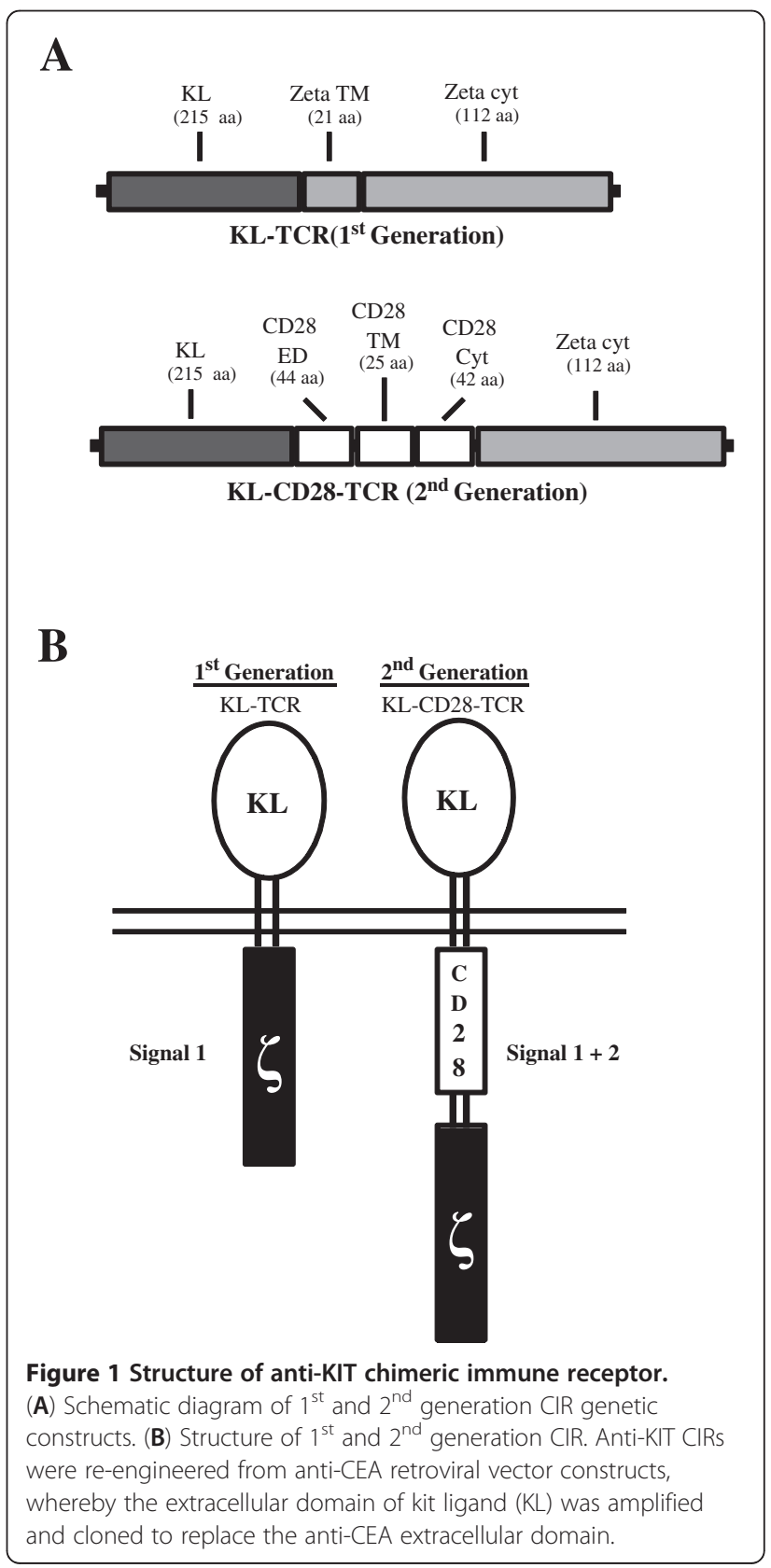




\section{Results}

Engineering of anti-KIT chimeric immune receptors and production of designer $\mathrm{T}$ cells

Our aim for this study was to construct and test the function of KIT-specific CIR expressed by human peripheral blood $\mathrm{T}$ cells for pre-clinical development. We based our anti-KIT CIR construct on our pre-existing anti-CEA format [7]. The anti-CEA $\mathrm{sFv}$ fragment was replaced with the extracellular domain of KL. $1^{\text {st }}$ and $2^{\text {nd }}$ gen constructs were prepared (Figure $1 \mathrm{~A}$ ). The $2^{\text {nd }}$ gen construct contains CD28 to provide co-stimulation. The $\mathrm{KL}$ component is expressed on the extracellular aspect of the CIR to enable interaction with KIT on the surface of target tumor cells (Figure 1B). We confirmed our constructs by direct DNA sequencing prior to transduction of activated lymphocytes (data not shown).

Following activation and transduction, CIR expression was confirmed by flow cytometry with an anti-KL antibody. Retroviral transduction of activated murine splenocytes (not shown), which we used as a preliminary assessment, resulted in mean $1^{\text {st }}$ and $2^{\text {nd }}$ gen CIR expression rates of $27 \%$ (range, 16-41). Following optimization of our protocol, transduction of activated human PBMC (Figure 2A) yielded mean transduction rates of $50 \%$ (range, 33-74) and 42\% (range, 24-62) for $1^{\text {st }}$ and $2^{\text {nd }}$ gen human $\mathrm{dTc}$ respectively, with no significant difference between the two CIR versions $(\mathrm{p}=0.67)$. After stimulation of PBMC with anti-CD3, anti-CD28 and IL2, $>70 \%$ of the cells were CD3+ (data not shown) and a central memory phenotype $(\mathrm{CD} 45 \mathrm{RO}+\mathrm{CD} 62 \mathrm{~L}+\mathrm{CCR7}+)$ predominated (Figure 2B) for both CD4+ and CD8+ T cells. Fewer than $30 \%$ of cells had a naïve (CD45RO-CD62L+) or effector memory (CD45RO+CD62L+CCR7-) phenotype, and less than $10 \%$ of transduced $\mathrm{T}$ cells from both generations had a regulatory $\mathrm{T}$ cell phenotype (CD25+FoxP3+) with no difference between the groups (data not shown). For $1^{\text {st }}$ gen $\mathrm{dTc}, 33.4 \%$ of $\mathrm{T}$ cells were CD $4+\mathrm{CD} 8$ - and $52.7 \%$
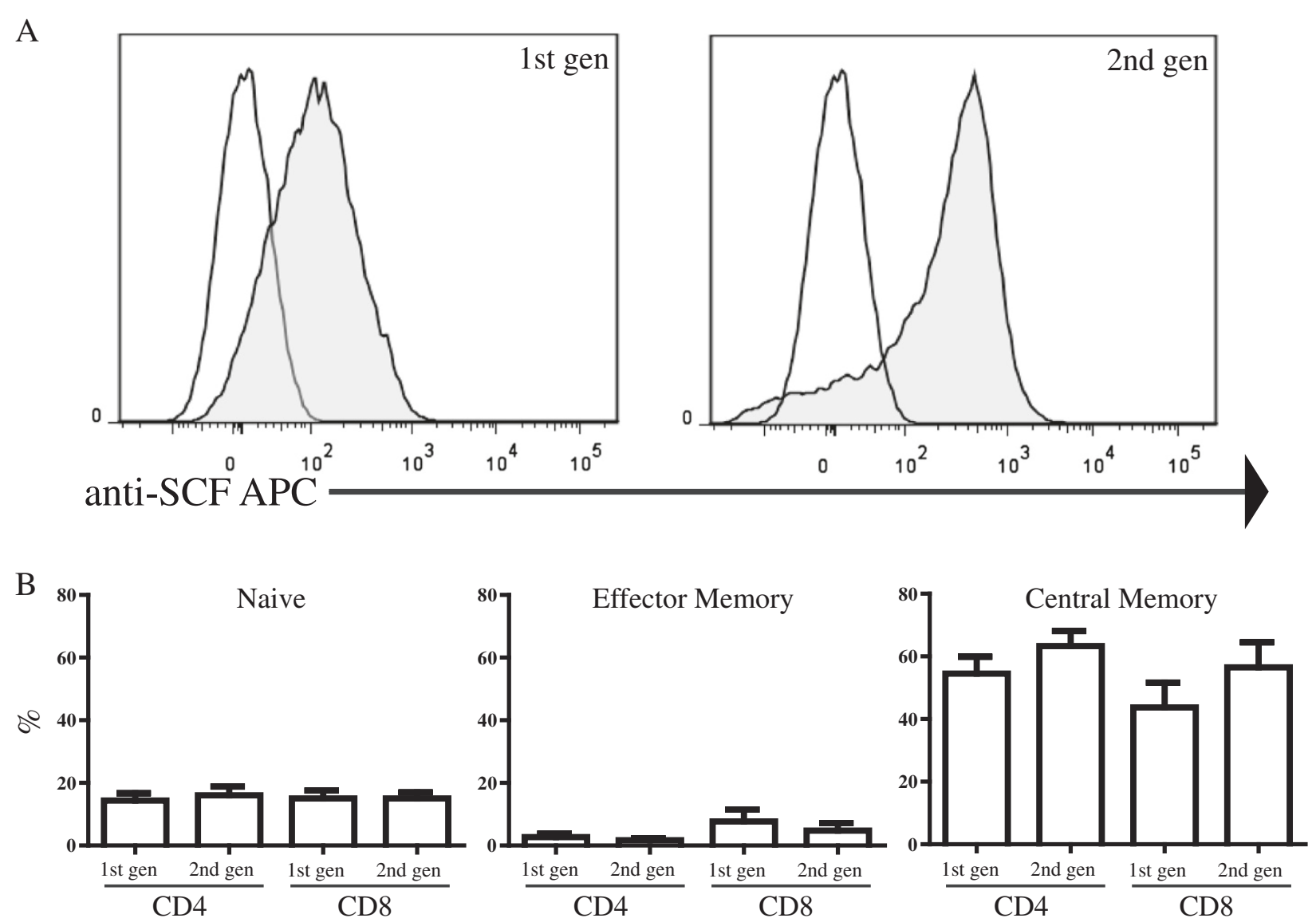

Figure 2 Transduction efficiency and phenotype of human anti-KIT designer T cells (dTc). (A) PBMC were isolated and primary human T cells activated and transduced with retrovirus expressing KIT-specific CIRs. Shaded histograms represent dTc and open histograms represent untransduced cells. (B) Flow cytometric analysis of the phenotype of $1^{\text {st }}$ and $2^{\text {nd }}$ generation $d T c$ demonstrated that T cells (CD4+ and CD8+ $T$ cells) of a central memory phenotype (CD45RO+CD62L+CCR7+) were in the majority. Naïve T cells were defined as (CD45RO-CD62L+). Data are representative of three or more repetitions. 
were CD8+CD4-, while the corresponding values for $2^{\text {nd }}$ gen $\mathrm{dTc}$ were $35.5 \%$ and $52.6 \%$. The CD4:CD8 ratio did not change after transduction or exposure to KIT+ tumor (not shown). For all subsequent experiments, dTc were used in bulk, without fractionating by CD4 or CD8 expression, in keeping with current clinical practice for dTc infusions.

\section{Proliferation of anti-KIT dTc in the presence of KIT+ tumor cells}

To test the proliferative capacity of human $\mathrm{T}$ cells expressing anti-KIT CIR, we cultured the dTc in the presence of two human KIT+ GIST cell lines, GIST882 and GIST48 $[14,16]$. In the presence of GIST882 and GIST48, dTc expressing either the $1^{\text {st }}$ or $2^{\text {nd }}$ gen antiKIT CIR proliferated to a greater extent when compared to control groups (CTRL) as determined by CFSE dilution (Figure 3A). When cultured with GIST882, 39\% of the $1^{\text {st }}$ gen and $47 \%$ of the $2^{\text {nd }}$ gen dTc divided ( $\mathrm{p}<0.001$ compared to CTRL), with no significant difference between the two CIR formats $(p=0.23$, Figure $3 B)$. Likewise, in the presence of imatinib resistant GIST48 cells,
$33-38 \%$ of the dTc divided after 3 days in culture which was significantly higher than CTRL cells $(\mathrm{p} \leq 0.03$ compared to CTRL), with no significant difference between the two CIR formats $(p=0.56$, Figure $3 C)$. The requirement of KIT + tumor cells for dTc proliferation was confirmed by the minimal proliferation that resulted when culturing dTc in the presence of KIT- GIST 48B cells, and CIR- activated T cells did not proliferate in the presence of KIT + tumor (data not shown). IFN $\gamma$ production confirmed dTc activation by KIT+ tumor and was found to be in the range of $462-475 \mathrm{pg} / \mathrm{ml}$, while production by CIR- $\mathrm{T}$ cells was negligible $(\mathrm{p}<0.001$, Figure 3D). Co-culture of anti-KIT dTc with KITcontrol tumor cells did not result in significant IFN $\gamma$ production (data not shown).

\section{Lysis of KIT+ tumor cells by anti-KIT designer T cells}

The hallmark of effective adoptive cellular immunotherapy is the ability of the product to lyse tumor cells in a specific fashion. To this end, we performed in vitro assays to determine if dTc expressing anti-KIT CIR were able to destroy GIST cells. We demonstrated that $2^{\text {nd }}$ gen $\mathrm{dTc}$ effectively
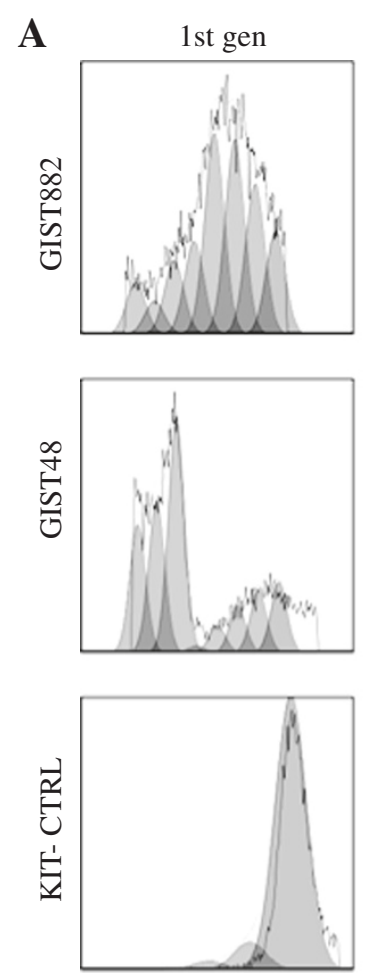

T CELL CFSE
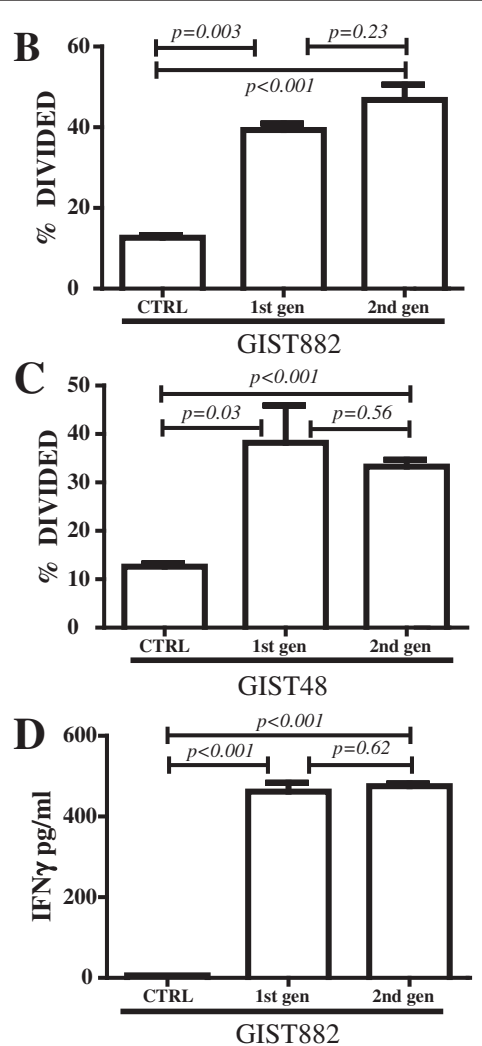

Figure 3 Human anti-KIT dTc retain proliferative ability in vitro. $1^{\text {st }}$ and $2^{\text {nd }}$ gen dTc were stimulated with human KIT+ GIST cell lines, GIST 882 and GIST 48. T cells were stained with CFSE and proliferation assessed by gating on CD3+ cells to measure CFSE dilution (A-C) and KIT- cells were used as a control. CIR- T cells did not proliferate in the presence of KIT+ tumor (not shown). (D) To confirm dTc activation by KIT+ GIST cell lines, IFNY production was measured by ELISA, and was found to be in the range of $462-475 \mathrm{pg} / \mathrm{ml}$, while that of untransduced CIR- T cells (CTRL) was negligible. Data are representative of three or more repetitions. 
lysed KIT+ tumor and were more effective than the $1^{\text {st }}$ gen format by $\mathrm{LDH}$ release (Figure 4A). To confirm our findings, we mixed CFSE-labeled irradiated tumor cells with unlabeled $\mathrm{T}$ cells. Tumor cell loss or death was measured by quantifying the decrease in CFSE fluorescence from remaining live cells. When compared to CTRL cells, $1^{\text {st }}$ gen and $2^{\text {nd }}$ gen $\mathrm{dTc}$ mediated significant decreases in the level of CFSE fluorescence and hence number of live tumor cells (Figures 4B,C). Having demonstrated that the anti-KIT dTc were stimulated to divide in vitro in response to KIT+ tumor and lyse KIT+ targets, we sought to measure the in vivo efficacy.

\section{In vivo assessment of anti-KIT dTc}

To determine the ability of anti-KIT dTc to traffic to, infiltrate, and limit growth of established tumor, we utilized a subcutaneous xenograft model. Human KIT+ GIST cells were injected subcutaneously into immunodeficient mice that were treated with tail vein injections of $1^{\text {st }}$ gen, $2^{\text {nd }}$ gen, or unmodified anti-KIT dTc 7 days later. Tumor measurements were performed in two dimensions $\left(\mathrm{mm}^{2}\right)$ and are expressed as median percentage change relative to the tumor size on initial day of treatment. IL2 therapy was given along with $\mathrm{dTc}$ for some groups because IL2 is known to enhance $\mathrm{T}$ cell function and may play a role in tumor clearance. In a single repetition, significant reductions in tumor growth were mediated by $1^{\text {st }}$ gen $\mathrm{dTc}$ without IL2 $(\mathrm{p}=0.05)$ and $2^{\text {nd }}$ gen $\mathrm{dTc}(\mathrm{p}<0.001)$ with IL2 (Figure $5 \mathrm{~A}$ ). When all data were pooled, both $1^{\text {st }}$ and $2^{\text {nd }}$ gen dTc had a significant impact on tumor growth in the absence of IL2 therapy. With IL2 support, $1^{\text {st }}$ gen dTc had a significant effect $(\mathrm{p}=0.05)$ while $2^{\text {nd }}$ gen $\mathrm{dTc}(\mathrm{p}=0.13)$ demonstrated a favorable trend (Figure $5 \mathrm{~B}$ ). $1^{\text {st }}$ gen $\mathrm{dTc}$ may be more reliant on IL 2 than $2^{\text {nd }}$ gen $d$ Tc because the presence of the co-stimulatory signal through the CD28 portion of the construct may reduce the dependence of $2^{\text {nd }}$ gen $\mathrm{dTc}$ on cytokines such as IL2. Data is further represented as tumor growth for each individual sample to demonstrate the range of values (Figure 5C). Following sacrifice, we harvested the tumors and confirmed the presence of adoptively transferred $\mathrm{dTc}$ and necrosis in animals treated with $1^{\text {st }}$ or $2^{\text {nd }}$ gen dTc (Figures $5 \mathrm{D}$ and E).

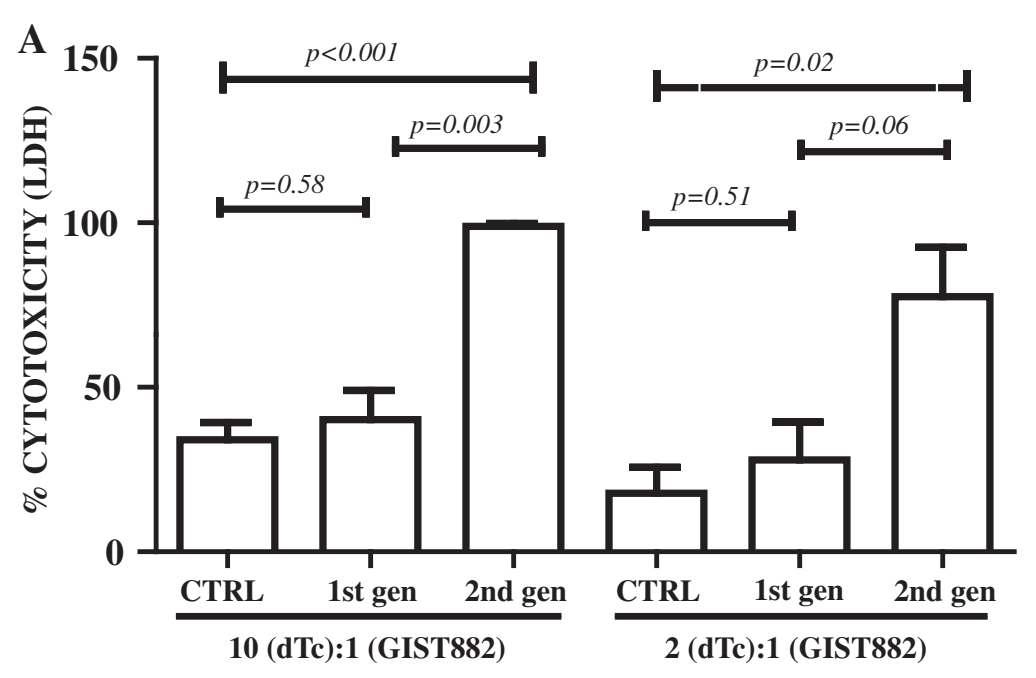

B
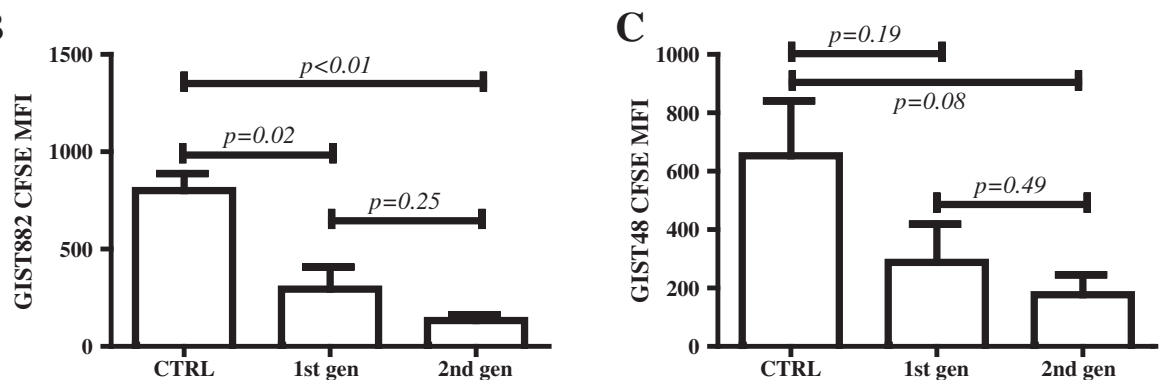

Figure 4 Ability of human anti-KIT dTc to effectively lyse KIT+ tumor cells. (A) LDH assay to evaluate enzymatic release following tumor cell lysis was performed on supernatant from co-culturing of $1^{\text {st }}$ and $2^{\text {nd }}$ generation dTc with irradiated GIST 882 cells. Maximal release was defined by the highest experimental values. (B-C) To confirm the cytotoxic ability of dTc, irradiated GIST 882 or GIST 48 cells were labeled with CFSE and cultured with unlabelled T cells. Tumor cell death was quantified by measuring the decrease in CFSE fluorescence by gating on remaining live cells. Data are representative of three or more repetitions. 


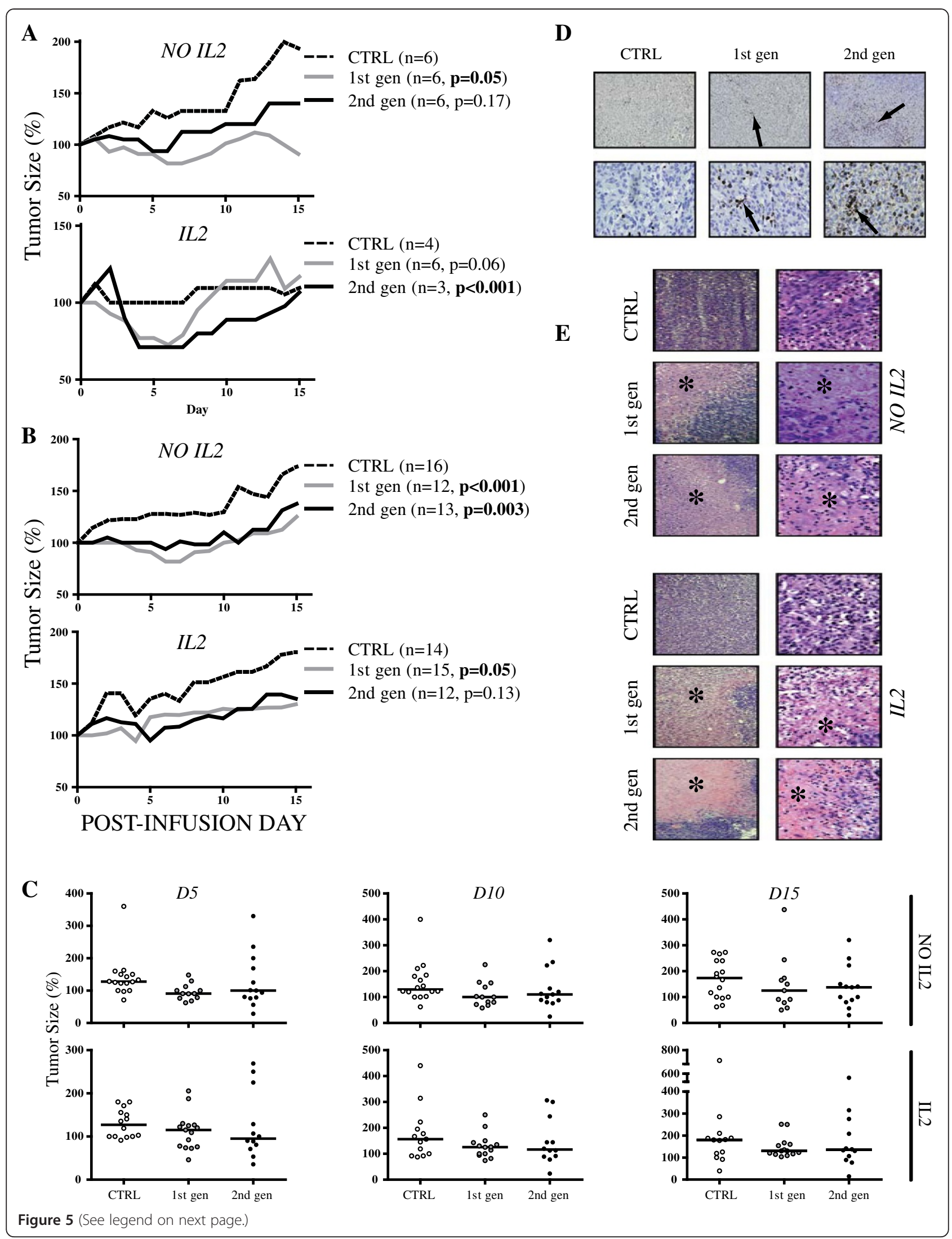


Figure $\mathbf{5}$ In vivo testing of human anti-KIT designer T cells. We used a subcutaneous xenograft model whereby GIST 882 cells were injected subcutaneously into immunodeficient mice prior to treatment with human anti-KIT dTc. Median results from a single representative experiment (A) and pooled data from 3 experiments (B) are shown. Activated CIR- T cells were used as negative controls. (C) Median tumor sizes at Day 5 , Day 10, and Day 15 post-infusion are indicated by horizontal bars along with individual tumor measurements represented by the data points. (D) We performed immunohistochemistry (top row 10x, bottom row 40x) to detect tumor infiltrating CD3+ T cells (arrows). (E) Routine H\&E was used to assess the degree of tumor necrosis (asterisks) in mice treated with $1^{\text {st }}$ or $2^{\text {nd }}$ gen $d T c$, both with and without supplemental IL2 (left column 10x, right column 40x).

\section{Discussion}

We have constructed a novel anti-KIT CIR that can be utilized to reprogram human $\mathrm{T}$ cells to recognize and kill KIT+ GIST tumors. The natural ligand for KIT, SCF, conferred anti-tumor specificity for the anti-KIT CIR and $\mathrm{T}$ cells were transduced with high levels of efficiency. Our in vitro studies confirmed that anti-KIT dTc proliferated and secreted IFN $\gamma$ in response to two KIT+ GIST cell lines, one of which was established from a GIST clinically resistant to kinase-inhibitor therapy with imatinib. The dTc were also able to lyse KIT+ cells in vitro. Using a xenograft model, we demonstrated that systemic infusions of $1^{\text {st }}$ and $2^{\text {nd }}$ gen anti-KIT $d T c$ resulted in significant reductions in tumor growth rates. Taken together, our initial study of anti-KIT dTc supports their further development as a novel treatment for KIT+ neoplasms, including those which have developed clinical resistance to kinase-inhibitor therapy.

Success with the clinical use of dTc has been reported for the treatment of chronic lymphocytic leukemia, melanoma, and synovial cell sarcoma $[11,17]$. DTc may offer a new therapeutic option for GIST treatment that can be used alone or in combination with other therapies, including TKIs. Imatinib has been reported to induce regulatory $\mathrm{T}$ cell apoptosis and its efficacy was enhanced by concurrent immunotherapy [18]. Adding imatinib to anti-KIT dTc infusions may augment efficacy through favorable immunomodulation within the tumor microenvironment, allowing the $\mathrm{dTc}$ to mediate enhanced tumor cell lysis.

Our histologic studies confirmed that anti-KIT dTc traffic to KIT+ tumors and mediate tumor necrosis after intravenous infusion. Few CTRL T cells were seen within the tumors following intravenous infusion, suggesting that either preferential trafficking or intratumoral proliferation accounted for the presence of anti-KIT dTc within the GIST xenografts. Although we demonstrated dTc within GIST xenografts, we speculate that the predominance of a central memory phenotype (CD62L+CCR7+CD45RO+) among anti-KIT dTc following production may have promoted preferential migration to lymphoid tissue, which we did not examine further $[19,20]$. Addition of IL-15 and IL-21 to promote an effector phenotype [21] may offer the potential of enhancing the efficacy of anti-KIT dTc. The optimal production method and
dTc subsets for treatment of KIT+ tumors remain to be determined.

Significant delays in tumor growth following a single $\mathrm{dTc}$ infusion in our in vivo model support the potential utility of anti-KIT dTc for the treatment of GIST. Yet, only one animal experienced a complete regression and several factors may have limited in vivo activity of the anti-KIT dTc. Multiple infusions may be necessary to achieve complete regression of established tumors, given that the efficacy of the anti-KIT dTc seemed to wane 7 days following a single infusion. When comparing the median tumor sizes at several time points, a small number of outliers appeared to have a significant impact on the analysis of the $2^{\text {nd }}$ gen groups. In addition, the absence of a normal immune cell repertoire in the immunodeficient mice may have limited the extent of the anti-tumor effect following dTc infusion. We speculate that tumor cell lysis, antigen release, and the associated inflammatory response may stimulate endogenous immunity which may contribute to tumor regression. The implications of a normal endogenous immune system for the in vivo activity of anti-KIT $\mathrm{dTc}$ require clarification through additional studies.

Several limitations of our data warrant consideration. Our findings did not support a significant or consistent benefit to either the presence of CD28 signaling in the $2^{\text {nd }}$ gen $\mathrm{dTc}$ or IL-2 infusion for the treatment of established GIST xenografts. The addition of the CD28 moiety to other CIR constructs has been shown to enhance $\mathrm{dTc}$ persistence and lytic function, although conflicting results have been reported $[7,22,23]$. The absence of a compelling advantage for the $2^{\text {nd }}$ gen $d T c$ compared to the $1^{\text {st }}$ gen in our model may be specific to the anti-KIT constructs and further testing will be required to explain the limited benefit of CD28 costimulation. In vitro, it has been shown that exogenous IL-2 was necessary in order for modified T cells to have a marked effect on tumor growth [23]. We speculate that immunodeficient mice did not show a significant response to supplemental IL-2 due to their lack of endogenous Treg that can deplete IL-2 from the environment [24]. Furthermore, Treg have been shown to directly inhibit the induction of IL-2 mRNA, which augments the requirement for exogenous IL-2 addition 
[17]. We are also unable to exclude the possibility that the modification of the $\mathrm{T}$ cells in some way altered their intrinsic responsiveness to IL-2 in vivo.

Finally, our in vivo murine model might not have permitted a full assessment of toxicity given that we utilized the human SCF moiety in the CIR. Expression of the KIT gene is essential for the development of normal hematopoiesis, proliferation, and migration of primordial germ cells and melanoblasts during embryogenesis as well as for the development of gastrointestinal pacemaker activity $[16,25]$. Although it may be reasonable to address this concern in a phase I trial with a small number of patients, development of suitable animal model prior to clinical studies would be preferable.

\section{Conclusions}

We have successfully produced anti-KIT dTc and have demonstrated their capacity for recognizing and killing KIT+ GIST cells. The present study establishes the basis for further investigation of anti-KIT dTc for the treatment of advanced GIST refractory to tyrosine kinase inhibitors. Study of anti-KIT dTc function in the context of an intact immune system will be informative, along with more detailed characterization of the phenotype of the $1^{\text {st }}$ and $2^{\text {nd }}$ gen $\mathrm{dTc}$. A phase I clinical trial will be required to demonstrate the safety of anti-KIT dTc in addition to their potential efficacy.

\footnotetext{
Abbreviations

CIR: Chimeric immune receptor; CTRL: Untransduced T cells; CFSE: Carboxyfluorescein diacetate succinimidyl ester; dTc: Designer T cells; FBS: Fetal bovine serum; Gen: Generation; GIST: Gastrointestinal stromal tumor; IMDM: Iscove's Modified Dulbecco's Medium; KIT: CD117; KL: KITligand; LDH: Lactate dehydrogenase; MFI: Mean fluorescence index; PBMC: Peripheral blood mononuclear cells; SCF: Stem cell factor; TIL: Tumor infiltrating lymphocytes; TKI: Tyrosine kinase inhibitor.
}

\section{Competing interests}

The authors declare that they have no competing interests.

\begin{abstract}
Authors' contributions
SCK - Conceived of the study and coordinated its design and execution, analyzed the data, wrote the manuscript, and created the figures. RB Performed in vivo tumor experiments, and in vitro designer T cell production. Assisted with the writing of the manuscript, data analysis, and figure production. SN - Performed in vitro assays and contributed to the writing of the manuscript. LL - Performed in vitro assays and contributed to the writing of the manuscript. MT - Assisted with the writing and editing of the manuscript and figures. DO - Assisted with construct design, performed in vitro designer T cell production, and reviewed the figures and text. CN Performed in vitro designer $\mathrm{T}$ cell production and assisted with in vivo experiments. NJE - Assisted with the writing and editing of the manuscript in addition to the study design. JAF - Assisted with writing of the manuscript, provided cell lines, and collaborated with the design and execution of in vitro and in vivo experiments. RPJ - Participated in study conception, chimeric antigen receptor design, data interpretation, and critically reviewed the figures and text. All authors read and approved the final manuscript.
\end{abstract}

\section{Acknowledgement}

The authors would like to thank Anthony Bais for his contributions to the retroviral vector construction and chimeric antigen receptor design, as well as the Kristen Ann Carr Fund for the generous support to carry out this project through the Murray F. Brennan Research Award.

\section{Author details}

'Roger Williams Medical Center, Department of Surgery, Providence, RI/ Boston University School of Medicine, Boston, MA, USA. ${ }^{2}$ Roger Williams Medical Center, Department of Medicine, Providence, RI/Boston University School of Medicine, Boston, MA, USA. 'Brigham and Women's Hospital and Harvard Medical School, Boston, MA, USA.

Received: 10 December 2012 Accepted: 8 February 2013 Published: 21 February 2013

\section{References}

1. Katz SC, DeMatteo RP: Gastrointestinal stromal tumors and leiomyosarcomas. J Surg Oncol 2008, 97:350-359.

2. Parkkila S, Lasota J, Fletcher JA, Ou WB, Kivela AJ, Nuorva K, Parkkila AK, Ollikainen J, Sly WS, Waheed A, et al: Carbonic anhydrase II. A novel biomarker for gastrointestinal stromal tumors. Mod Pathol 2010, 23:743-750.

3. Dematteo RP, Ballman KV, Antonescu CR, Maki RG, Pisters PW, Demetri GD, Blackstein ME, Blanke CD, von Mehren M, Brennan MF, et al: Adjuvant imatinib mesylate after resection of localised, primary gastrointestinal stromal tumour: a randomised, double-blind, placebo-controlled trial. Lancet 2009, 373:1097-1104.

4. Janicke RU, Engels IH, Dunkern T, Kaina B, Schulze-Osthoff K, Porter AG: lonizing radiation but not anticancer drugs causes cell cycle arrest and failure to activate the mitochondrial death pathway in MCF-7 breast carcinoma cells. Oncogene 2001, 20:5043-5053.

5. Rosenberg SA, Spiess P, Lafreniere R: A new approach to the adoptive immunotherapy of cancer with tumor-infiltrating lymphocytes. Science 1986, 233:1318-1321.

6. Rosenberg SA, Restifo NP, Yang JC, Morgan RA, Dudley ME: Adoptive cell transfer: a clinical path to effective cancer immunotherapy. Nat Rev Cancer 2008, 8:299-308.

7. Emtage PC, Lo AS, Gomes EM, Liu DL, Gonzalo-Daganzo RM, Junghans RP: Second-generation anti-carcinoembryonic antigen designer T cells resist activation-induced cell death, proliferate on tumor contact, secrete cytokines, and exhibit superior antitumor activity in vivo: a preclinical evaluation. Clin Cancer Res 2008, 14:8112-8122.

8. Sadelain M, Riviere I, Brentjens R: Targeting tumours with genetically enhanced T lymphocytes. Nat Rev Cancer 2003, 3:35-45.

9. Schumacher TN: T-cell-receptor gene therapy. Nat Rev Immunol 2002, 2:512-519.

10. Stauss HJ, Cesco-Gaspere M, Thomas S, Hart DP, Xue SA, Holler A, Wright G, Perro M, Little AM, Pospori C, et al: Monoclonal T-cell receptors: new reagents for cancer therapy. Mol Ther 2007, 15:1744-1750.

11. Porter DL, Levine BL, Kalos M, Bagg A, June CH: Chimeric antigen receptormodified T cells in chronic lymphoid leukemia. N Engl J Med 2011, 365:725-733.

12. Robbins PF, Morgan RA, Feldman SA, Yang JC, Sherry RM, Dudley ME, Wunderlich JR, Nahvi AV, Helman LJ, Mackall CL, et al: Tumor regression in patients with metastatic synovial cell sarcoma and melanoma using genetically engineered lymphocytes reactive with NY-ESO-1. J Clin Oncol 2011, 29:917-924.

13. Tuveson $D A$, Willis $N A$, Jacks $T$, Griffin JD, Singer $S$, Fletcher $C D$, Fletcher JA, Demetri GD: STI571 inactivation of the gastrointestinal stromal tumor c-KIT oncoprotein: biological and clinical implications. Oncogene 2001, 20:5054-5058.

14. Bauer S, Yu LK, Demetri GD, Fletcher JA: Heat shock protein 90 inhibition in imatinib-resistant gastrointestinal stromal tumor. Cancer Res 2006, 66:9153-9161.

15. Muhlenberg T, Zhang Y, Wagner AJ, Grabellus F, Bradner J, Taeger G, Lang H, Taguchi T, Schuler M, Fletcher JA, Bauer S: Inhibitors of deacetylases suppress oncogenic KIT signaling, acetylate HSP90, and induce apoptosis in gastrointestinal stromal tumors. Cancer Res 2009, 69:6941-6950.

16. Takagi S, Saito Y, Hijikata A, Tanaka S, Watanabe T, Hasegawa T, Mochizuki S, Kunisawa J, Kiyono H, Koseki H, et al: Membrane-bound human SCF/KL promotes in vivo human hematopoietic engraftment and myeloid differentiation. Blood 2012, 119:2768-2777.

17. Thornton AM, Shevach EM: CD4+CD25+ immunoregulatory T cells suppress polyclonal T cell activation in vitro by inhibiting interleukin 2 production. J Exp Med 1998, 188:287-296. 
18. Balachandran VP, Cavnar MJ, Zeng S, Bamboat ZM, Ocuin LM, Obaid H, Sorenson EC, Popow R, Ariyan C, Rossi F, et al: Imatinib potentiates antitumor $\mathrm{T}$ cell responses in gastrointestinal stromal tumor through the inhibition of Ido. Nat Med 2011, 17:1094-1100.

19. Ley K, Bullard DC, Arbones ML, Bosse R, Vestweber D, Tedder TF, Beaudet AL: Sequential contribution of $\mathrm{L}$ - and $\mathrm{P}$-selectin to leukocyte rolling in vivo. J Exp Med 1995, 181:669-675.

20. Yoshida R, Nagira M, Kitaura M, Imagawa N, Imai T, Yoshie O: Secondary lymphoid-tissue chemokine is a functional ligand for the CC chemokine receptor CCR7. J Biol Chem 1998, 273:7118-7122.

21. Pouw N, Treffers-Westerlaken E, Kraan J, Wittink F, ten Hagen T, Verweij J Debets R: Combination of IL-21 and IL-15 enhances tumour-specific cytotoxicity and cytokine production of TCR-transduced primary T cells. Cancer Immunol Immunother 2010, 59:921-931.

22. Krause A, Guo HF, Latouche JB, Tan C, Cheung NK, Sadelain M: Antigen-dependent CD28 signaling selectively enhances survival and proliferation in genetically modified activated human primary T lymphocytes. J Exp Med 1998, 188:619-626.

23. Lo AS, Ma Q, Liu DL, Junghans RP: Anti-GD3 chimeric sFv-CD28/T-cell receptor zeta designer T cells for treatment of metastatic melanoma and other neuroectodermal tumors. Clin Cancer Res 2010, 16:2769-2780.

24. Shevach EM: Mechanisms of foxp3+ T regulatory cell-mediated suppression. Immunity 2009, 30:636-645.

25. Broudy VC: Stem cell factor and hematopoiesis. Blood 1997, 90:1345-1364.

doi:10.1186/1479-5876-11-46

Cite this article as: Katz et al:: Anti-KIT designer T cells for the treatment of gastrointestinal stromal tumor. Journal of Translational Medicine 2013 11:46.

\section{Submit your next manuscript to BioMed Central and take full advantage of:}

- Convenient online submission

- Thorough peer review

- No space constraints or color figure charges

- Immediate publication on acceptance

- Inclusion in PubMed, CAS, Scopus and Google Scholar

- Research which is freely available for redistribution 